\title{
RNA-binding protein altered expression and mislocalization in multiple sclerosis
}

Authors: Katsuhisa Masaki, MD, PhD; Yoshifumi Sonobe, PhD; Ghanashyam Ghadge, PhD; Peter Pytel, MD; Paula Lépine, MSc; Florian Pernin, MSc; Qiao-Ling Cui, MD-PhD; Jack P. Antel, MD; Stephanie Zandee, PhD; Alexandre Prat, MD, PhD and Raymond P. Roos, MD

Katsuhisa Masaki, Yoshifumi Sonobe, Ghanashyam Ghadge, Raymond P. Roos, Departments of Neurology, University of Chicago Medical Center, Chicago, IL, USA Peter Pytel, Departments of Pathology, University of Chicago Medical Center, Chicago, IL, USA

Paula Lépine, Stephanie Zandee, Alexandre Prat' Neuroimmunology Research Laboratory, Centre du Recherche du Centre Hospitalier de l'Université de Montréal (CRCHUM), Montreal, QC, Canada

Florian Pernin, Qiao-Ling Cui, Jack P. Antel, Neuroimmunology Unit, Montreal Neurological Institute, McGill University, Montreal, QC, Canada

Search Terms: All Demyelinating disease (CNS), Multiple sclerosis, Autoimmune diseases

\section{Submission Type: Article}

Title Character count: 80

Number of Figures: 5

Number of Supplementary Tables: 2 
Number of Supplementary Figures: 1

Word count of Abstract: 217

Word Count of Paper: 3,451

Corresponding Author:

Raymond P. Roos

Department of Neurology, University of Chicago Medical Center,

5841 S. Maryland Ave., Chicago, IL 60637

Phone: 773-702-9905

Fax: 773-702-9060

rroos@neurology.bsd.uchicago.edu

Katsuhisa Masaki: masakikatsuhisa@yahoo.co.jp

Yoshifumi Sonobe: ysonobe@neurology.bsd.uchicago.edu

Ghanashyam Ghadge: Gghadge@neurology.bsd.uchicago.edu

Peter Pytel: Peter.Pytel@uchospitals.edu

Paula Lépine: lepinepaula@yahoo.fr

Florian Pernin: florian.pernin@mail.mcgill.ca

Qiao-Ling Cui: qiaoling.cui@mcgill.ca

Jack P. Antel: jack.antel@mcgill.ca

Stephanie Zandee: stephanie.zandee@umontreal.ca

Alexandre Prat: a.prat@umontreal.ca

Raymond P. Roos: rroos@neurology.bsd.uchicago.edu 


\section{Financial Disclosures:}

Katsuhisa Masaki- Reports no disclosures

Yoshifumi Sonobe- Reports no disclosures

Ghanashyam Ghadge- Reports no disclosures

Peter Pytel- Reports no disclosures

Paula Lépine- Reports no disclosures

Florian Pernin- Reports no disclosures

Qiao-Ling Cui- Reports no disclosures

Jack P. Antel- Reports no disclosures

Stephanie Zandee- Reports no disclosures

Alexandre Prat- Reports no disclosures

Raymond P. Roos- Reports no disclosures

Statistical Analysis conducted by Katsuhisa Masaki, MD, PhD, Department of Neurology, University of Chicago Medical Center

Study Funded by the NIH National Institute of Neurological Disease and Stroke (NINDS) (R21NS096569) (RPR), Amyotrophic Lateral Sclerosis Association (RPR), Progressive MS Alliance (BRAVEin MS) (JA), Lohengrin Foundation, Steps4 Doug, John and Patricia McDonald, and Barbara and Marc Posner. 


\section{Abstract}

Objective: Nuclear depletion and mislocalization of RNA-binding proteins (RBPs) transactivation response DNA-binding protein of $43 \mathrm{kDa}$ (TDP-43) and fused in sarcoma (FUS) are thought to contribute to the pathogenesis of a number of disorders, including amyotrophic lateral sclerosis (ALS). We recently found that TDP-43 as well as polypyrimidine tract binding protein (PTB) have decreased expression and mislocalization in oligodendrocytes in demyelinated lesions in an experimental mouse model of multiple sclerosis (MS) caused by Theiler's murine encephalomyelitis virus infection.

Methods: The latter finding prompted us to investigate TDP-43, FUS, and PTB in the demyelinated lesions of MS and in in vitro cultured human brain-derived oligodendrocytes. Results: We found: i) mislocalized TDP-43 in oligodendrocytes in active lesions in some MS patients; ii) decreased PTB1 expression in oligodendrocytes in mixed active/inactive demyelinating lesions; iii) decreased nuclear expression of PTB2 in neurons in cortical demyelinating lesions; iv) nuclear depletion of TDP-43 in oligodendrocytes under metabolic stress induced by low glucose/low nutrient conditions compared to optimal culture conditions.

Conclusion: TDP-43 has been found to have a key role in oligodendrocyte function and viability, while PTB is important in neuronal differentiation, suggesting that altered expression and mislocalization of these RBPs in MS lesions may contribute to the pathogenesis of demyelination and neurodegeneration. Our findings also identify nucleocytoplasmic transport as a target for treatment. 


\section{Introduction}

Multiple sclerosis (MS) is a chronic inflammatory disease of the central nervous system (CNS) characterized pathologically by sharply demarcated plaques of demyelination along with axonal injury and reactive astrocytosis. Clinically MS often runs a relapsing-remitting course that is reflected in different histopathologic patterns of demyelinating plaques, which are typically described as active, mixed active/inactive or "chronic" ${ }^{\text {. Progressive }}$ clinical disability is linked to demyelination in the white matter and cerebral cortex as well as cortical atrophy. The etiology and pathological mechanisms that drive white matter demyelination and neurodegeneration remain poorly understood.

Here we identify abnormalities in the expression and localization of RNA-binding proteins (RBPs) in MS lesions and in oligodendrocytes exposed in vitro to metabolic stress conditions. RBPs bind to double or single stranded RNA in cells and participate in the formation of ribonucleoprotein complexes (reviewed in ${ }^{2}$ ). These proteins play a key role in RNA biology, such as splicing, polyadenylation, mRNA stabilization, mRNA localization, and translation. Most RBPs reside in the nucleus in order to carry out their function, and shuttle across the nuclear membrane in association with mRNAs. Decreased expression and mislocalization of RBPs, including trans-activation response (TAR) DNA-binding protein of $43 \mathrm{kDa}$ (TDP-43) and fused in sarcoma (FUS), have been implicated in the pathogenesis of amyotrophic lateral sclerosis (ALS) and frontotemporal dementia ${ }^{2}$.

We recently investigated the expression and mislocalization of RBPs in infections with Theiler's murine encephalomyelitis virus (TMEV), a member of the Cardiovirus genus of Picornaviridae ${ }^{3}$. Polypyrimidine tract binding protein (PTB) is known to have an abnormal 
nuclear localization in TMEV-infected cells as a result of interference of nucleocytoplasmic transport by a TMEV protein (reviewed in ${ }^{4}$ ); the mislocalization has been hypothesized to play a role in neuronal dysfunction in TMEV-induced disease ${ }^{5}$. We questioned whether other RBPs were also abnormally distributed in TMEV infections, and might contribute to disease pathogenesis. We found that TDP-43 and FUS, in addition to PTB, were mislocalized in TMEV-infected neural cells, including oligodendrocytes, in demyelinating lesions. Since TMEV-induced immune-mediated demyelination serves as an experimental model of MS, we carried out the present investigation in order to determine whether the expression pattern and localization of these RBPs were also abnormal in MS. We focused on three RBPs - TDP-43, FUS, and PTB (which included paralogs PTB1 and PTB2) since they have been found to play an important role in TMEV infections and/or ALS.

In the present study, we found a number of examples of abnormal expression and mislocalization of RBPs in MS lesions and in in vitro cultured oligodendrocytes: i) mislocalization of TDP-43 in oligodendrocytes in active demyelinating lesions; ii) decreased expression of PTB1 in oligodendrocytes in mixed active/inactive demyelinating lesions; iii) decreased nuclear expression of PTB2 in neurons in cortical demyelinating lesions; iv) nuclear depletion of TDP-43 in cultured oligodendrocytes under metabolic stress conditions. These results suggest that altered expression of RBPs in demyelinating lesions of MS may disrupt key cellular processes, and thereby contribute to the pathogenesis of demyelination and neurodegeneration. A recent publication demonstrated that TDP-43 is important for oligodendrocyte survival and myelination ${ }^{6}$. In addition, PTB is known to be critically important for splicing repression and neuronal differentiation ${ }^{7,8}$. The significance of these two RBPs to central nervous system function emphasizes the 
relevance of our results, and the potential importance of nucleocytoplasmic transport as a target for treatment. 


\section{Methods}

\section{Ethics statement, Human Samples, Tissue preparation and immunohistochemistry/immunofluorescence (see Supplement)}

\section{Staging of demyelinating lesions}

We classified MS plaques into three stages ${ }^{1}$ based on the density of macrophages: i) active - lesions densely and diffusely infiltrated with macrophages, ii) mixed active/inactive - lesions with macrophages restricted to the periphery, and iii) inactive - lesions with no increase in macrophage numbers within the plaque. We classified cortical plaques into three subtypes: leukocortical (involving both white matter and cortex), intracortical, and subpial (superficial cortical).

\section{Semi-quantitative analysis of RBPs mislocalization}

Sections from blocks of cerebral cortex and white matter in all MS cases were stained with DAB or by fluorescence for RBPs that included TDP-43, PTB1, PTB2 and FUS. A semiquantitative assessment of RBP nuclear depletion and mislocalization or decreased expression in demyelinating lesions was performed by taking digital photographs with a CMOS camera at a resolution of $1636 \times 1088$ pixels with a $\times 20(0.75 \mathrm{NA})$ objective. At least 3 different photographs of areas of one lesion that were more than $1 \mathrm{~mm}$ apart from each other in $\mathrm{x}$ and $\mathrm{y}$ directions were randomly taken for every demyelinating lesion. At least 100 neuronal or glial cells per each area were identified on the basis of cytological features $^{11}$ and scored based on the degree of mislocalization or decreased nuclear expression of RBPs compared to normal appearing white matter from the same case 
stained at the same time: - no or minimal; + mild (10-30 cells); ++ moderate (30-100 cells); +++ cases prominent (>100 cells (see Table e-1).

\section{In vitro studies}

Oligodendrocytes were isolated and cultured from samples of 4 surgical resections (3 adults cases: 2 males, ages 57 and 38 and 1 female, age 51 and one pediatric case: male, age 7) that did not involve malignancies, as previously described ${ }^{12,13}$. The tissue was from a site distant from visible pathology. The isolation technique involved initial dissociation of tissue using trypsin digestion followed by Pespan style="font-family:Arial"> gradient centrifugation to remove myelin. The total cell fraction was plated onto a non-coated flask that was kept overnight at $37^{\circ} \mathrm{C}$ to allow adhesion of the microglia fraction. Floating cells were then recovered (>90\% were $\mathrm{O}^{+}$) and plated into 12 well poly-L-lysine and extracellular matrix-coated chamber slides $(30,000$ cells per well) in defined medium (referred to as N1) consisting of Dulbecco's modified essential medium DMEM-F12 (Sigma-Aldrich) supplemented with N1 (Sigma-Aldrich), 0.01\% bovine serum albumin,1\% penicillin-streptomycin, B27 (Invitrogen), platelet-dreived growth factor with two A subunits (10 ng/ml), basic fibroblast growth factor $(10 \mathrm{ng} / \mathrm{ml})$, and triiodothyronine $(2 \mathrm{nM})$ (SigmaAldrich). After 4 days, media in individuor with DMEM with $0.25 \mathrm{~g} / \mathrm{L}$ glucose (referred to as low glucose (LG). After an additional 2 or 6 days of $\mathrm{N} 1$ or LG treatment, cells were incubated with monoclonal $\mathrm{O} 4$ antibody and propidium iodide $(\mathrm{PI})$ for $15 \mathrm{~min}$ at $37^{\circ} \mathrm{C}$. Cells were fixed with $4 \%$ paraformaldehyde for 10 minutes at room temperature and then stained with a secondary antibody directed against $\mathrm{O}$, goat anti-mouse IgM conjugated to AF-647 (SouthernBiotech). After permeabilization buffer with $0.1 \%$ Triton $\mathrm{X}-100$, the cells were stained with polyclonal anti-TDP-43 antibody (Proteintech) for 1 hour at $37^{\circ} \mathrm{C}$ 
followed by goat anti-rabbit polyclonal antibody conjugated to AF-488 and Hoescht 33258

(Invitrogen) for 30 minutes. Cells were then examined using an epifluorescent microscope (Zeiss, Oberkochen, Germany) to determine the percent of $\mathrm{O} 4$ cells that were $\mathrm{PI}^{+}$cells and $\%$ of cells that showed predominantly nuclear versus cytoplasmic distribution of TDP-43. Data were derived by blinded observers counting 75-100 cells per condition. Data between LG and N1 conditions were compared using a paired t-test.

\section{Statistical analysis}

Data were analyzed using GraphPad Prism version 7.0a and are expressed as means \pm standard error of the mean. Significance was assessed using Student's t test, and P values less than 0.05 were considered statistically significant.

\section{Data availability statement}

Any data not published within the article will be shared by request from any qualified investigator in anonymized form. 


\section{Results}

\section{TDP-43 in ALS}

In ALS, TDP-43 is depleted from the nucleus in some motor neurons, and localized in aggregates in the cytoplasm (Fig 1A, arrows), while other neurons and glial cells have TDP-43 in its normal location in the nucleus (Fig 1A, B, arrowhead), At times phosphorylated TDP-43 (pTDP-43) is present in the cytoplasmic aggregates (Fig 1C) Two other RBPs, PTB2 and FUS, maintain their normal nuclear localization in cells in the same region that have TDP-43 mislocalization (Fig. 1D, F). PTB1 was not detected in motor neurons (Fig. 1E), since it is known to have a limited distribution in this cell type ${ }^{14}$. In contrast to these finding in ALS, a predominant nuclear localization of TDP-43 is present in neurons and oligodendrocytes in human control CNS tissue (Fig. 1G, H).

\section{Altered localization and expression of RBPs in oligodendrocytes in white matter plaques}

TDP-43 was mislocalized to the cytoplasm in glial cells in active demyelinating lesions from patients MS\#3 and 13 to a moderate degree (Table e-1) (MS\#3 - Fig. 2A-H). Double immunofluorescence demonstrated that this mislocalization was present in CNPasepositive oligodendrocytes to a significant extent (Fig. 2I, J); the nuclear depletion and cytoplasmic mislocalization was statistically significantly greater $(P=0.0003)$ when compared with oligodendrocytes in the periplaque white matter (PPWM) (Fi.g 2I, J). Similar findings were also present in all three active demyelinating plaques in the case of MS\#13 (Fig. e-1). The TDP-43 mislocalization was not a result of cellular death since the cell and its nucleus had normal morphology and there was no evidence of cleaved 
caspase-3 staining. Although the oligodendrocytes in active plaques in the CNS tissue from MS\#3 and 13 exhibited TDP-43 mislocalization, this was not the case with the active plaques from a biopsy of a tumefactive MS lesion in MS\#14 and from another MS case with three active plaques. No abnormalities were found with respect to the normal nuclear localization and expression of FUS in active plaques.

In addition to our finding of mislocalization of TDP-43 in some active plaques, there was decreased expression of PTB1 in oligodendrocytes in mixed active/inactive demyelinating lesions (MS\# 2, 6, 10-13, Table e-1); however, cytoplasmic mislocalization of PTB1 was not seen in these lesions. In addition, TDP-43 and FUS were present in the nucleus in mixed active/inactive demyelinating lesions. The decreased expression of PTB1 ranged from mild to prominent (Table e-1). Although PTB1 had its expected nuclear staining in normal appearing white matter (NAWM) in the case of MS\#10 (Fig. 3B, E), there was markedly decreased expression in the nuclei and cytoplasm of CNPase-positive oligodendroglia in demyelinated and partly remyelinated lesions (Fig. 3C, D, F, G); this lesion had macrophages present in the periphery as typical of active-inactive plaques. The decrease in expression was statistically significant compared to oligodendrocytes in the PPWM (P = 0.0007) (Fig. 3H). Cells with decreased PTB1 expression had normal morphology and there was no evidence of caspase-3 staining. In the case of MS\#6, PTB1 expression was also diminished in mixed active/inactive demyelinating lesion (Fig. 3I-K); again, macrophages were present in the periphery of this plaque. The decrease in expression was statistically significant compared to oligodendrocytes in the PPWM $(\mathrm{P}=$ 0.0003) (Fig. 3K). 


\section{Alteration of RBPs in cortical plaques}

Leukocortical mixed active/inactive demyelinating lesions from patients MS\#2, 8, 10-12 had mild to moderate diminution of PTB2 expression in neurons within the demyelinated area compared to neurons in adjacent normal-appearing gray matter (NAGM) (MS\#2 - Fig. 4A-H, MS\#10 - Fig. 4I-L) (Table e-1). Although the expression of PTB2 was decreased in the nucleus in these cells, there was no evidence of cytoplasmic mislocalization or aggregate formation of PTB2 (Fig. 4E-G). The decrease in PTB2 expression in cortical neurons in leukocortical plaques in the case of MS\#2 and \#10 was statistically significant compared to cortical neurons in the PPGM $(\mathrm{P}<0.0001)$ (Fig. $4 \mathrm{H}, \mathrm{L})$. In contrast to these findings, the expression of TDP-43 and FUS in neurons in leukocortical plaques, and of TDP-43, FUS and PTB2 in neurons of intracortical and subpial plaques had a normal expression in the nuclei and did not differ from that in NAGM (Table e-1).

\section{TDP-43 proteinopathy in in vitro cultured primary human oligodendrocytes}

We cultured primary human oligodendrocytes in a low glucose medium in order to model metabolic stress conditions thought to occur in MS lesions ${ }^{12,13}$. As shown in Fig. $5 A$, there is only a low level of cell death under N1 conditions at day 2 in culture. Levels modestly increase under LG conditions, as previously described ${ }^{12,13}$. By day 6 , however, there was a significant increase in cell death under LG conditions. The percent of O4 cells showing predominantly nuclear TDP-43 staining was significantly reduced in the LG-treated cultures compared to the $\mathrm{N} 1$ counterparts (mean $53 \%$ for LG vs $82 \%$ for $\mathrm{N} 1$; P=0.015, Fig. 5B and illustrated in Fig. 5C). Nuclear depletion was observed in virtually all $\mathrm{PI}+$ cells, as shown with the $\mathrm{PI}+$ cells in Fig. 5C. Of note, the percent of $\mathrm{Pl}$ - cells with nuclear depletion 
was greater in LG cultures versus $\mathrm{N} 1$ cultures (mean $56 \%$ for $L G$ vs $86 \%$ for $\mathrm{N} 1$; $\mathrm{P}=$ 0.014, $\mathrm{n}=3$, data not shown). 


\section{Discussion}

Abnormalities of expression and localization of RBPs have been described in a number of diseases, including ALS, Huntington's disease, and viral infections ${ }^{2}$. In the present study, we focused on TDP-43, FUS, and PTB because these RBPs have an important impact on RNA biology and also because their mislocalization is thought to influence the pathogenesis of ALS and TMEV infections.

TDP-43 is a ubiquitously expressed RBP that predominantly resides in the nucleus, but shuttles across the nuclear membrane in association with mRNAs ${ }^{15}$. A hallmark of almost all cases of ALS is disruption of nucleocytoplasmic trafficking with resultant nuclear depletion, cytoplasmic mislocalization, aggregation, cleavage, and phosphorylation of TDP-43 in neural cells ${ }^{16-18}$. The decreased expression and mislocalization or TDP-43 are thought to cause abnormalities of splicing and RNA metabolism as well as add to nucleocytoplasmic transport disruption, thereby contributing to ALS pathogenesis ${ }^{19-22}$. It is likely that cytoplasmic mislocalization of other RBPs in addition to TDP-43 adds to the cellular dysfunction in ALS ${ }^{23}$.

In the present study, we demonstrate a number of abnormalities in expression and localization of RBPs in MS lesions and in in vitro cultured oligodendrocytes. We found that TDP-43 was mislocalized in oligodendrocytes in demyelinated lesions in MS, as was the case in TMEV infections. Of note, TDP-43 is known to bind to 100 s of mRNAs, including mRNAs encoding PLP, myelin basic protein, myelin oligodendrocyte glycoprotein, and myelin-associated glycoprotein, and to play a key role in RNA metabolism and splicing ${ }^{24}$. 
Importantly and relevant to our findings is a recent report that an experimental decrease in expression of TDP-43 in mature oligodendrocytes in mice leads to demyelination and RIPK1-mediated necroptosis of oligodendrocytes ${ }^{6}$; of note, necroptosis has been reported to occur in MS as well as experimental models of MS ${ }^{25}$. A conclusion of that investigation was that the TDP-43 knockdown led to a reduction in myelin gene expression, and that TDP-43 is indispensable for oligodendrocyte survival and demyelination ${ }^{6}$. These findings suggest that nuclear depletion and mislocalization of TDP-43 in MS lesions would similarly lead to demyelination and, in some cases, death of oligodendrocytes.

We found a decrease in PTB1 in oligodendrocytes in mixed active/inactive demyelinating lesions, as well as a decrease in PTB2 in neurons in cortical plaques. PTB1 and PTB2 are paralogous RBPs that are encoded by related genes ${ }^{7}$. PTB1 is not expressed in mature neurons and muscle, while PTB2 is expressed in these cells and others. These RBPs function in regulating alternative splicing, and also play a role in translation, mRNA stability, and polyadenylation. The control of splicing is especially important in the CNS because of the myriad of mRNA isoforms that have key roles in development and function. Splicing in oligodendrocytes and neurons in MS demyelinated regions is likely impacted by the nuclear depletion and cytoplasmic mislocalization of PTB. Importantly, PTB is involved in the differentiation of neural precursor cells ${ }^{7,8}$. In this way, PTB2 nuclear depletion and cytoplasmic mislocalization in neurons of cortical plaques may contribute to neurodegeneration and the cognitive decline associated with MS.

In summary, we found that there is disruption of TDP-43 and PTB expression and localization that varies in different neural cell types in MS plaques. This variation may have 
resulted from differences in the protein composition of the nuclear pore complex in different cell types ${ }^{26}$. Furthermore, different subtypes of MS lesions may manifest continuing changes of RBP abnormalities over time because of the dynamic nature of demyelinating lesions and the varying inflammatory milieu. It may be that this changeable and very dynamic nature of MS lesions is the reason that active plaques from MS\#14 had a normal localization of TDP-43. Also of importance is the fact that MS is a heterogeneous disease - and therefore it is not surprising that forms of MS that are different from classical and typical cases may not share the same RBP abnormalities seen in more prototypic cases of MS. Perhaps this was the reason that an active plaque from a biopsy from a tumefactive lesion of MS\#4 (in a patient who had only one additional clinical problem over decades of observation) had a normal localization of TDP-43 (Table e-1).

The nucleocytoplasmic transport abnormalities in MS that we identified may have resulted from a number of possible causes. Probably most relevant are reports that inflammation can lead to mislocalization of proteins in neural cells. Correia et al. ${ }^{27}$ found that mislocalization of TDP-43 occurred in: cultured microglia and astrocytes following exposure to lipopolysaccharide (LPS); motor neuron-like NSC-34 cells after treatment with tumor necrosis factor-alpha (TNFa); and motor neurons of mutant TDP-43 transgenic mice following LPS intraperitoneal injections. Kim et al. ${ }^{28}$ reported that treating neuronal cultures with glutamate and TNFa led to mislocalization of HDAC1 with resultant axonal damage. The latter investigators also detected abnormal cytoplasmic localization of HDAC1 in damaged axons in MS patients and in mice with cuprizone-induced demyelination. Salapa et al. ${ }^{29}$ found that interferon- $y$ led to cytoplasmic mislocalization of heterogeneous ribonuclear protein (hnRNP) A1, an RBP. These investigators also reported that neurons in 
a region of an MS brain (in which no pathology was described) had nuclear depletion and cytoplasmic mislocalization of hnRNP A1, which was aggregated in stress granules.

Our in vitro culture conditions were selected to model metabolic stress conditions that are thought to occur in MS lesions ${ }^{12,13}$. Antel and colleagues previously showed that these conditions were associated with an initial withdrawal of cell processes, modelling the dying-back of oligodendrocyte processes observed in MS lesions (as well as cuprizoneinduced demyelination ${ }^{30}$ and TMEV-induced demyelination ${ }^{31}$. These changes were reversible if culture conditions were restored within a subsequent 48 hours. If continued past this time, however, significant cell death occurs by 6 days, as shown in Fig. 5A, with activation of an autophagy response. In the current study, we found TDP-43 nuclear depletion was increased under LG conditions after 2 days in culture, a time when cell death levels as detected by PI staining were low. Importantly, we specifically observed nuclear depletion in cells that were still $\mathrm{PI}$ negative, in addition to $\mathrm{PI}+$ cells that also showed nuclear depletion of TDP-43. These results are consistent with in situ data showing nuclear depletion of TDP-43 in oligodendrocytes with intact oligodendrocyte cell bodies. Of note, TNFa also leads to dying back of cultured oligodendrocytes, although in this case it was observed in newborn rat-derived oligodendrocytes ${ }^{12}$. The combined in vitro and in situ results suggest that the TDP-43 nuclear depletion reflects a cellular stress response that could be mediated both by the metabolic conditions and inflammatory mediators of MS lesions. Of note, no difference in TDP-43 transcripts was found in a microarray data set derived from oligodendrocytes under N1 vs LG conditions for 2 days ${ }^{12}$, suggesting that any change in TDP-43 protein levels is a result of translational regulation, presumably from stress, such as from low glucose ${ }^{32}$ or inflammatory factors, triggering the 
integrated stress response. Activation of the integrated stress response has been previously implicated in the pathogenesis of MS ${ }^{33}$.

Our results suggest that correcting the expression and localization of RBPs in MS may ameliorate disease. In addition, this direction may lead to normal localization of key transcription factors and proteins that are required for efficient myelination and remyelination in oligodendrocytes and oligodendrocyte precursor cells ${ }^{34-37}$. Importantly, nuclear export inhibitors have been found to attenuate myelin oligodendrocyte glycoprotein-induced experimental autoimmune encephalomyelitis (as well as kainic acidinduced axonal damage) by limiting areas of myelin damage, preserving myelinated and unmyelinated axon integrity, and decreasing inflammation ${ }^{38}$. Nuclear export inhibitors have also been found to attenuate disease and to be neuroprotective in experimental models of ALS ${ }^{39}$, including a mutant TDP-43 mouse model ${ }^{19}$, and Huntington's disease ${ }^{40}$ (which, like ALS, has abnormalities of nucleocytoplasmic transport). Furthermore, nucleocytoplasmic transport is being targeted in patients with cancer in addition to neurological diseases and a clinical trial with a nuclear export inhibitor is in progress in ALS.

Altered nucleocytoplasmic transport leading to abnormal expression and mislocalization of RBPs and other macromolecules may not only contribute to the demyelination and neurodegeneration in MS, but also underlie a number of other disease states, both infectious as well as non-infectious. The availability of drugs that target nucleocytoplasmic transport may provide new and novel treatment possibilities for these disorders. 


\section{Acknowledgments}

We thank the UCLA Human Brain and Spinal Fluid Resource Center and the Rocky Mountain MS Center Tissue Bank (supported in part by a grant from the National Multiple Sclerosis Society) for specimens from autopsied MS cases.

Appendix. Authors

\begin{tabular}{lll}
\hline Name & Location & Contribution \\
\hline Katsuhisa Masaki, MD, & University of Chicago & Conception and design of \\
PhD & Medical Center & the study; drafting the \\
\hline Yoshifumi Sonobe, PhD & University of Chicago & Conception and design of \\
& Medical Center & the study \\
\hline Ghanashyam Ghadge PhD & University of Chicago & Conception and design of \\
& Medical Center & the study \\
\hline Peter Pytel, MD & University of Chicago & Acquisition of samples and \\
& Medical Center & analysis of the data \\
\hline Plorian Pernin, MSc & Centre du Recherche du & Acquisition of samples and \\
\hline Ciao-Ling Cui, MD-PhD & McGill University & acquisition of samples and \\
\hline & l'Université de Montréal & acquisition of samples and \\
\hline
\end{tabular}




\begin{tabular}{lll}
\hline Jack P. Antel, MD & McGill University & analysis of the data \\
\hline Stephanie Zandee, PhD & Centre du Recherche du & Acquisition of samples and \\
& analysis of the data \\
\hline Ilexandre Prat, MD, PhD & Centre Hospitalier de & Acquisition of samples and \\
& I'Université de Montréal & analysis of the data \\
& Centre du Recherche du & \\
\hline Raymond P. Roos, MD & University of Chicago & Conception and design of \\
& Medical Center & the study; drafting the \\
& & manuscript
\end{tabular}




\section{References}

1. Kuhlmann T, Ludwin S, Prat A, et al. An updated histological classification system for multiple sclerosis lesions. Acta Neuropathol. 2017;133:13-24.

2. Nussbacher JK, Batra R, Lagier-Tourenne C, Yeo GW. RNA-binding proteins in neurodegeneration: Seq and you shall receive. Trends Neurosci. 2015;38:226-236. doi: 210.1016/j.tins.2015.1002.1003. Epub 2015 Mar 1019.

3. Masaki K, Sonobe Y, Ghadge G, et al. TDP-43 proteinopathy in Theiler's murine encephalomyelitis virus infection. PLoS Pathog. 2019;15:e1007574.

4. Roos RP. Pathogenesis of Theiler's murine encephalomyelitis virusinduced disease. In: Semler BL, Wimmer E, editors. Molecular biology of picornaviruses. Washington, DC: ASM Press; 2002. p. 427-435.

5. Pilipenko EV, Viktorova EG, Guest ST, et al. Cell-specific proteins regulate viral RNA translation and virus-induced disease. EMBO J. 2001;20:6899-6908. doi: 6810.1093/emboj/6820.6823.6899.

6. Wang J, Ho WY, Lim K, et al. Cell-autonomous requirement of TDP-43, an ALS/FTD signature protein, for oligodendrocyte survival and myelination. Proc Natl Acad Sci U S A. 2018;115:E10941-E10950. doi: 10910.11073/pnas.1809821115. Epub 1809822018 Oct 1809821129.

7. Hu J, Qian H, Xue Y, Fu XD. PTB/nPTB: master regulators of neuronal fate in mammals. Biophys Rep. 2018;4:204-214.

8. Linares $\mathrm{AJ}$, Lin $\mathrm{CH}$, Damianov $\mathrm{A}$, et al. The splicing regulator PTBP1 controls the activity of the transcription factor Pbx1 during neuronal differentiation. Elife. 2015;4:e09268. 
9. Polman $\mathrm{CH}$, Reingold SC, Banwell $\mathrm{B}$, et al. Diagnostic criteria for multiple sclerosis: 2010 revisions to the McDonald criteria. Ann Neurol. 2011;69:292-302.

10. Dhaeze T, Tremblay L, Lachance C, et al. CD70 defines a subset of proinflammatory and CNS-pathogenic $\mathrm{TH} 1 / \mathrm{TH} 17$ lymphocytes and is overexpressed in multiple sclerosis. Cell Mol Immunol. 2019;16:652-665.

11. Garcia-Cabezas MA, John YJ, Barbas H, Zikopoulos B. Distinction of Neurons, Glia and Endothelial Cells in the Cerebral Cortex: An Algorithm Based on Cytological Features. Front Neuroanat. 2016;10:107.

12. Cui QL, Khan D, Rone M, et al. Sublethal oligodendrocyte injury: A reversible condition in multiple sclerosis? Ann Neurol. 2017;81:811-824.

13. Rone MB, Cui QL, Fang J, et al. Oligodendrogliopathy in Multiple Sclerosis: Low Glycolytic Metabolic Rate Promotes Oligodendrocyte Survival. J Neurosci. 2016;36:46984707.

14. Boutz PL, Stoilov P, Li Q, et al. A post-transcriptional regulatory switch in polypyrimidine tract-binding proteins reprograms alternative splicing in developing neurons. Genes Dev. 2007;21:1636-1652. doi: 1610.1101/gad.1558107.

15. Buratti E, Brindisi A, Giombi M, et al. TDP-43 binds heterogeneous nuclear ribonucleoprotein $\mathrm{A} / \mathrm{B}$ through its $\mathrm{C}$-terminal tail: an important region for the inhibition of cystic fibrosis transmembrane conductance regulator exon 9 splicing. J Biol Chem. 2005;280:37572-37584.

16. Neumann M, Sampathu DM, Kwong LK, et al. Ubiquitinated TDP-43 in frontotemporal lobar degeneration and amyotrophic lateral sclerosis. Science. 2006;314:130-133. 
17. Arai T, Hasegawa M, Akiyama $H$, et al. TDP-43 is a component of ubiquitin-positive tau-negative inclusions in frontotemporal lobar degeneration and amyotrophic lateral sclerosis. Biochem Biophys Res Commun. 2006;351:602-611.

18. Igaz LM, Kwong LK, Xu Y, et al. Enrichment of C-terminal fragments in TAR DNAbinding protein-43 cytoplasmic inclusions in brain but not in spinal cord of frontotemporal lobar degeneration and amyotrophic lateral sclerosis. Am J Pathol. 2008;173:182-194.

19. Chou CC, Zhang Y, Umoh ME, et al. TDP-43 pathology disrupts nuclear pore complexes and nucleocytoplasmic transport in ALS/FTD. Nat Neurosci. 2018;21:228-239.

20. Lagier-Tourenne C, Polymenidou M, Cleveland DW. TDP-43 and FUS/TLS: emerging roles in RNA processing and neurodegeneration. Hum Mol Genet. 2010;19:R46-64.

21. Polymenidou M, Lagier-Tourenne $C$, Hutt KR, et al. Long pre-mRNA depletion and RNA missplicing contribute to neuronal vulnerability from loss of TDP-43. Nat Neurosci. $2011 ; 14: 459-468$.

22. Purice MD, Taylor JP. Linking hnRNP Function to ALS and FTD Pathology. Front Neurosci. 2018;12:326.

23. Conlon EG, Fagegaltier D, Agius P, et al. Unexpected similarities between C9ORF72 and sporadic forms of ALS/FTD suggest a common disease mechanism. Elife. 2018;7.:37754. doi: 37710.37554/eLife.37754.

24. Polymenidou M, Lagier-Tourenne $C$, Hutt KR, et al. Long pre-mRNA depletion and RNA missplicing contribute to neuronal vulnerability from loss of TDP-43. Nat Neurosci. 2011;14:459-468. doi: 410.1038/nn.2779. Epub 2011 Feb 1027.

25. Ofengeim D, Ito $\mathrm{Y}$, Najafov A, et al. Activation of necroptosis in multiple sclerosis. Cell Rep. 2015;10:1836-1849. doi: 1810.1016/j.celrep.2015.1802.1051. 
26. Raices M, D'Angelo MA. Nuclear pore complex composition: a new regulator of tissuespecific and developmental functions. Nat Rev Mol Cell Biol. 2012;13:687-699. doi: 610.1038/nrm3461.

27. Correia AS, Patel P, Dutta K, Julien JP. Inflammation Induces TDP-43 Mislocalization and Aggregation. PLoS One. 2015;10:e0140248. doi: 0140210.0141371/journal.pone.0140248. eCollection 0142015.

28. Kim JY, Shen S, Dietz K, et al. HDAC1 nuclear export induced by pathological conditions is essential for the onset of axonal damage. Nat Neurosci. 2010;13:180-189.

29. Salapa HE, Johnson C, Hutchinson C, et al. Dysfunctional RNA binding proteins and stress granules in multiple sclerosis. J Neuroimmunol. 2018;324:149156.:10.1016/j.jneuroim.2018.1008.1015. Epub 2018 Aug 1029.

30. Ludwin SK, Johnson ES. Evidence for a "dying-back" gliopathy in demyelinating disease. Ann Neurol. 1981;9:301-305.

31. Rodriguez M. Virus-induced demyelination in mice: "dying back" of oligodendrocytes. Mayo Clin Proc. 1985;60:433-438.

32. Yang R, Wek SA, Wek RC. Glucose limitation induces GCN4 translation by activation of Gcn2 protein kinase. Mol Cell Biol. 2000;20:2706-2717. e

33. Way SW, Popko B. Harnessing the integrated stress response for the treatment of multiple sclerosis. Lancet Neurol. 2016;15:434-443.

34. Dai J, Bercury KK, Jin W, Macklin WB. Olig1 Acetylation and Nuclear Export Mediate Oligodendrocyte Development. J Neurosci. 2015;35:15875-15893.

35. Gottle P, Kury P. Intracellular Protein Shuttling: A Mechanism Relevant for Myelin Repair in Multiple Sclerosis? Int J Mol Sci. 2015;16:15057-15085. 
36. Gottle P, Sabo JK, Heinen A, et al. Oligodendroglial maturation is dependent on intracellular protein shuttling. J Neurosci. 2015;35:906-919.

37. Nakahara J, Kanekura K, Nawa M, et al. Abnormal expression of TIP30 and arrested nucleocytoplasmic transport within oligodendrocyte precursor cells in multiple sclerosis. J Clin Invest. 2009;119:169-181.

38. Haines JD, Herbin O, de la Hera B, et al. Nuclear export inhibitors avert progression in preclinical models of inflammatory demyelination. Nat Neurosci. 2015;18:511-520. doi: 510.1038/nn.3953. Epub 2015 Feb 1023.

39. Zhang K, Donnelly CJ, Haeusler AR, et al. The C9orf72 repeat expansion disrupts nucleocytoplasmic transport. Nature. 2015;525:56-61.

40. Grima JC, Daigle JG, Arbez N, et al. Mutant Huntingtin Disrupts the Nuclear Pore Complex. Neuron. 2017;94:93-107.e106. 


\section{Figure Legends}

Figure 1. Expression pattern of RBPs in ALS and a control patient.

(A-F) A case of sporadic ALS. (A) TDP-43 is expressed normally in the nucleus of some spinal cord motor neurons (arrowhead), but depleted from the nucleus of affected motor neurons, forming aggregates (large arrows). (B) TDP-43 is localized in the nuclei of glial cells in spinal cord white matter. (C) A cytoplasmic inclusion in spinal cord motor neurons contains phosphorylated TDP-43 (pTDP-43). As expected in normal motor neurons, (D) FUS is present in the nucleus, (E) PTB1 is not present, and (F) PTB2 is present in the nucleus. (G, H) A control patient with myasthenia gravis. Expression of TDP-43 is mainly seen in the nuclei of cortical neurons $(G)$ and white matter oligodendrocytes $(H)$. Scale bars: $50 \mu \mathrm{m}(\mathrm{A}, \mathrm{B}), 20 \mu \mathrm{m}(\mathrm{C}-\mathrm{G})$ and $10 \mu \mathrm{m}(\mathrm{H})$.

Figure 2. Altered expression of PTB1 and TDP-43 in oligodendrocytes of MS plaques.

(A-G) An active and demyelinating lesion from MS\#3. (A) HE staining shows perivascular inflammation with mononuclear cell infiltration. (B, C) Immunostaining for PLP and CD68 identifies a marked loss of myelin with dense infiltration of macrophages. (D) Numerous CD68-positive macrophages are seen in the perivascular area and parenchyma of the lesion center. (E) Foamy macrophages phagocytosing PLP-positive myelin debris. (F-H) Boundary of active demyelinating lesion of MS\#3. (F, H) TDP-43 is localized in the nuclei of glial cells in peri-plaque white matter (PPWM). (F, G) TDP-43 is mislocalized to the cytoplasm of glial cells in a demyelinating lesion. (I) Double immunofluorescence shows mislocalization of TDP-43 in CNPase-positive oligodendrocytes at the edge of a demyelinating plaque $(\mathrm{H}$, arrowheads). (J) TDP-43 mislocalization in CNPase-positive 
oligodendrocytes. TDP-43 mislocalization in oligodendrocytes is significantly greater in demyelinating lesions than PPWM. Each dot for this quantitation and subsequent ones represents a photograph from a separate region of the plaque. Scale bars: $1 \mathrm{~mm}(A-C), 50$ $\mu \mathrm{m}(\mathrm{D}-\mathrm{F}, \mathrm{I})$ and $20 \mu \mathrm{m}(\mathrm{G}, \mathrm{H})$.

Figure 3. Reduced expression of PTB1 in oligodendrocytes of demyelinating lesions (A-H) Mixed active/inactive and demyelinating subcortical white matter lesion from MS\#10. (A-D) Double immunostaining for PTB1 (brown) and MBP (pink). (A) Macroscopic view of demyelinating subcortical lesion. Immunoreactivity for MBP is sharply demarcated in a subcortical area that has no detectable PTB1. (B) Immunoreactivity for PTB1 is present in the nucleus of glial cells, including oligodendrocytes, in NAWM. (C) Nuclear expression of PTB1 is diminished in an incompletely remyelinated area. (D) Expression of PTB1 is markedly decreased in glial cell nuclei in the demyelinated lesion. (E-G) Double immunofluorescence for PTB1 and CNPase. While immunoreactivity for PTB1 is preserved in the nuclei of CNPase-positive oligodendrocytes in NAWM (E), nuclear PTB1 is decreased in the remyelinated area $(F)$ and markedly depleted in oligodendrocytes in the lesion center (G). (H) Frequency of decreased PTB1 expression in CNPase-positive oligodendrocytes. Decreased PTB1 in oligodendrocytes is significantly frequent in demyelinating lesions than PPWM. (I-K) Mixed active/inactive and demyelinating white matter lesion from MS\#6 (I) Double immunofluorescence shows that nuclear expression of PTB1 is markedly diminished in the demyelinating lesion. (J) Higher magnification of PTB1 expression in the demyelinating lesion and normal-appearing white matter (NAWM). Although PTB1 is localized in nuclei of CNPase-positive oligodendrocytes of NAWM, PTB1 is decreased in CNPase-positive oligodendrocytes of the demyelinating lesion. (K) 
Decreased PTB1 expression in oligodendrocytes in active-inactive demyelinating lesions is significantly more frequent than in PPWM. Scale bars: $1 \mathrm{~mm}(A), 100 \mu \mathrm{m}(\mathrm{I}), 50 \mu \mathrm{m}(\mathrm{B}-\mathrm{D})$, $20 \mu \mathrm{m}(\mathrm{J})$ and $10 \mu \mathrm{m}(\mathrm{E}-\mathrm{G})$.

Figure 4. Reduced expression of PTB2 in neurons of cortical demyelinating lesions.

(A, B) Serial sections of a mixed active/inactive demyelinating lesion. (A) HE stain shows hypocellularity, and (B) immunostaining for PLP shows sharply demarcated periventricular demyelination including (C) cortical demyelination (arrowheads), which is above the dotted line. (D) CD68-positive macrophages are restricted to the periphery of the lesion (arrowheads). (E-G) Higher magnification of double immunofluorescence of square area (at edge of cortical demyelination) in Panel C. (E) PTB2 has normal expression in the nuclei of neurons in the non-affected area of the gray matter (above the dashed line) (F). In contrast, the expression of PTB2 is markedly decreased in neurons in the demyelinated area of the gray matter (below the dashed line) $(\mathrm{G})$. (H) Frequency of decreased PTB2 expression in cortical neurons. Decreased PTB2 in cortical neurons is significantly more frequent in cortical demyelinating lesions than PPGM. (I-L) Leukocortical mixed active/inactive demyelinating lesion MS\#10. (I) HE stain shows subcortical white matter lesion. (J) The cortex above the dashed line and within the lesion is demyelinated. (K) A higher magnification of the region within the rectangle in panel $\mathrm{J}$ includes the boundary of cortical demyelination. PTB2 expression is diminished in the demyelinated region of the cortex, while PTB2 is preserved in the cortical neurons in same layer of PPGM. (L) Frequency of decreased PTB2 expression in cortical neurons. Decreased PTB2 in cortical neurons is significantly more frequent in cortical demyelinating lesions than PPGM. Scale bars: $5 \mathrm{~mm}(\mathrm{~A}, \mathrm{~B}), 1 \mathrm{~mm}(\mathrm{C}, \mathrm{D}, \mathrm{I}, \mathrm{J}), 100 \mu \mathrm{m}(\mathrm{K}), 50 \mu \mathrm{m}(\mathrm{E})$ and $10 \mu \mathrm{m}(\mathrm{F}, \mathrm{G})$. 
Figure 5. Nuclear depletion of TDP-43 in human primary OLs cultured in vitro under LG conditions. Data were derived from 3 adult cases and 1 pediatric case with no history of MS. (A) Cell death of human OLs was assessed using propidium iodide (PI) staining at 2 and 6 days under optimal (N1) and metabolic stress (LG- low glucose) culture conditions. (B) Depletion of nuclear expression of TDP-43 in cutures of oligodendrocytes after 2 days of treatment with LG compared to N1 condition. Solid lines (adult cases) and dashed line (pediatric case) connect cultures of oligodendrocytes obtained from the same biopsy tissue. (C) Representative images showing immunostained oligodendrocytes 2 days under N1 and LG conditions. From left side: DAPI (blue), O4 (gray), TDP-43 (green), and TDP43 merged with PI (green and red respectively). Arrows show cells with nuclear expression of TDP-43; arrow heads show TDP-43 nuclear-depleted PI- cells; stars show TDP-43 nuclear-depleted $\mathrm{PI}+$ cells. Scale bar $=10 \mu \mathrm{m}$. ${ }^{*} \mathrm{P}<0.05,{ }^{* *} \mathrm{P}<0.01$. 


\section{Supplemental Data}

Figure e-1: TDP-43 mislocalization in oligodendrocytes of active demyelinating lesion of MS.

(A) Double immunofluorescence for TDP-43 and CNPase in inactive demyelinating lesion from MS\#6. The dotted line shows the boundary of demyelinating lesion and periplaque white matter (PPWM). Nuclear expression of TDP-43 is seen in the demyelinating lesion as well as PPWM. (B-D) Double immunofluorescence for TDP-43 and CNPase in active demyelinating lesion from MS\#13. (B) Nuclear expression of TDP-43 is seen in PPWM, while nuclear staining of TDP-43 is markedly diminished in the demyelinating lesion. (C) Higher magnification of double immunofluorescence. Nuclear TDP-43 is depleted in CNPase-positive oligodendrocyte of the active demyelinating lesion, whereas TDP-43 is expressed in the nuclei of oligodendrocytes of PPWM. (D) Frequency of TDP-43 mislocalization in CNPase-positive oligodendrocytes. TDP-43 mislocalization in oligodendrocytes is significantly higher in demyelinating lesions than PPWM. Scale bars: $100 \mu \mathrm{m}(\mathrm{A}, \mathrm{B})$ and $10 \mu \mathrm{m}(\mathrm{C})$. 
bioRxiv preprint doi: https://doi.org/10.1101/829457; this version posted November 5, 2019. The copyright holder for this preprint (which was not certified by peer review) is the author/funder. All rights reserved. No reuse allowed without permission.

Figure 1

\section{Sporadic ALS}
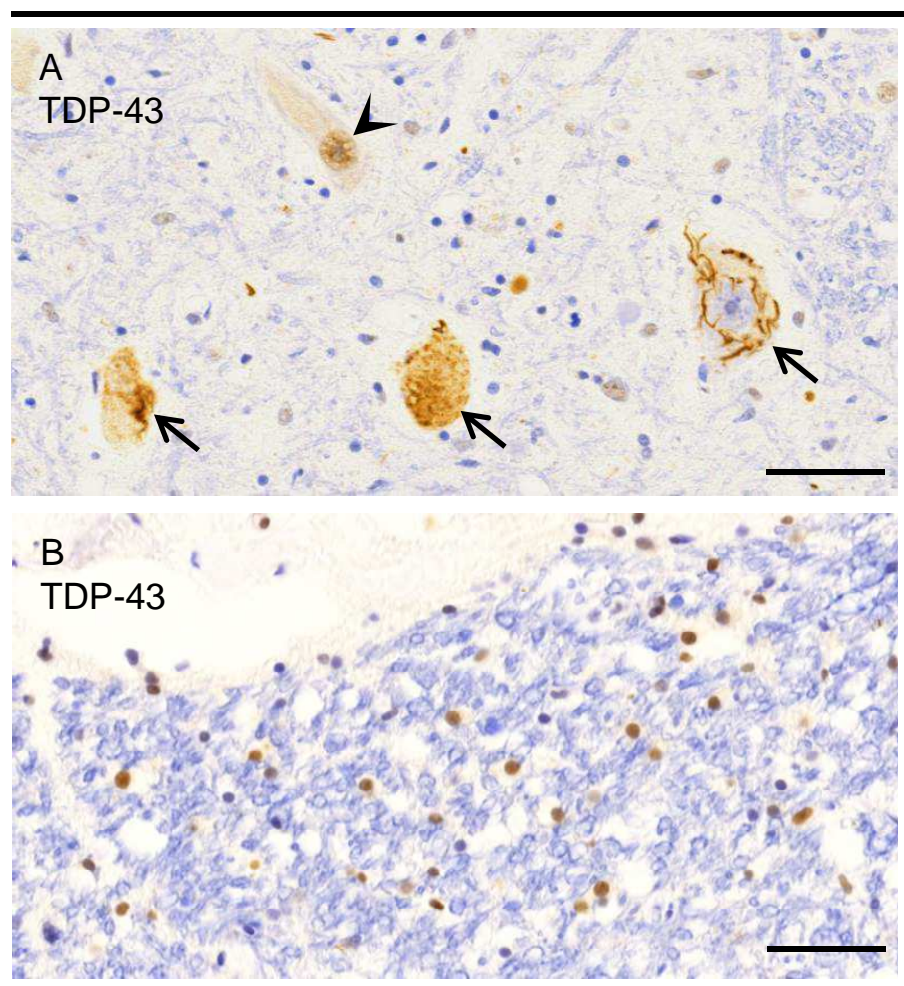
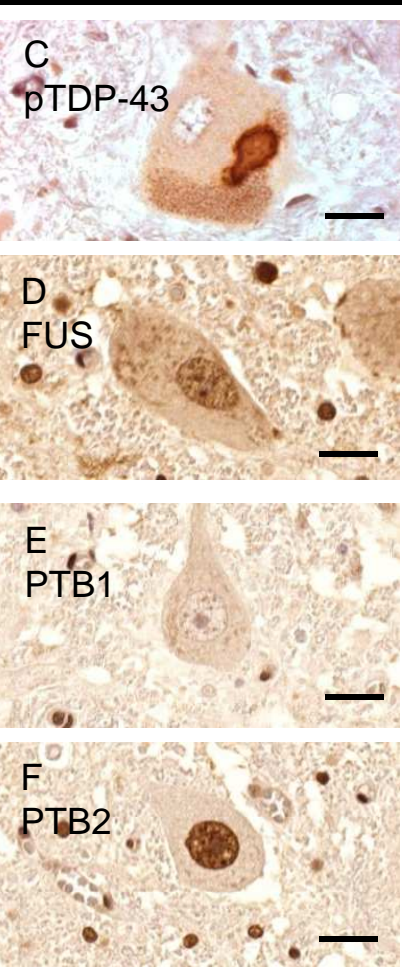

Myasthenia gravis
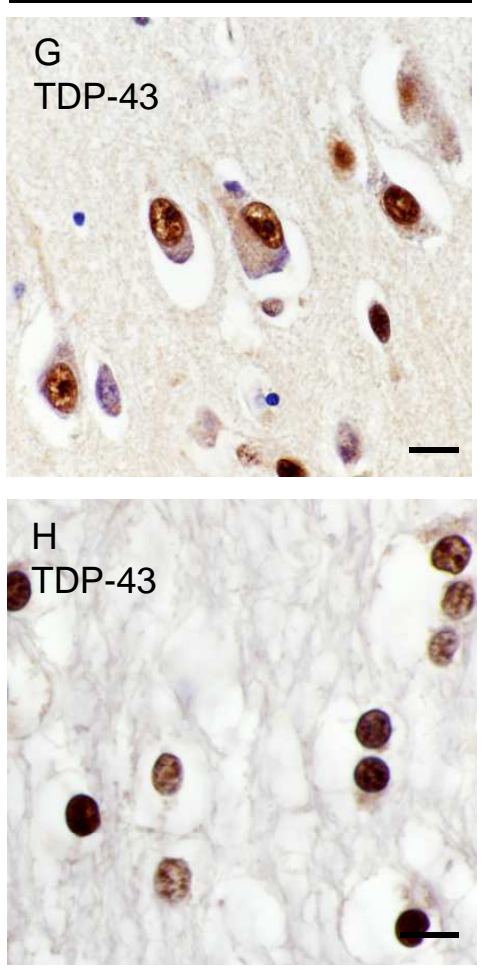
bioRxiv preprint doi: https://doi.org/10.1101/829457; this version posted November 5, 2019. The copyright holder for this preprint (which was not certified by peer review) is the author/funder. All rights reserved. No reuse allowed without permission.

\section{Figure 2}

Active and demyelinating lesion (MS\#3)
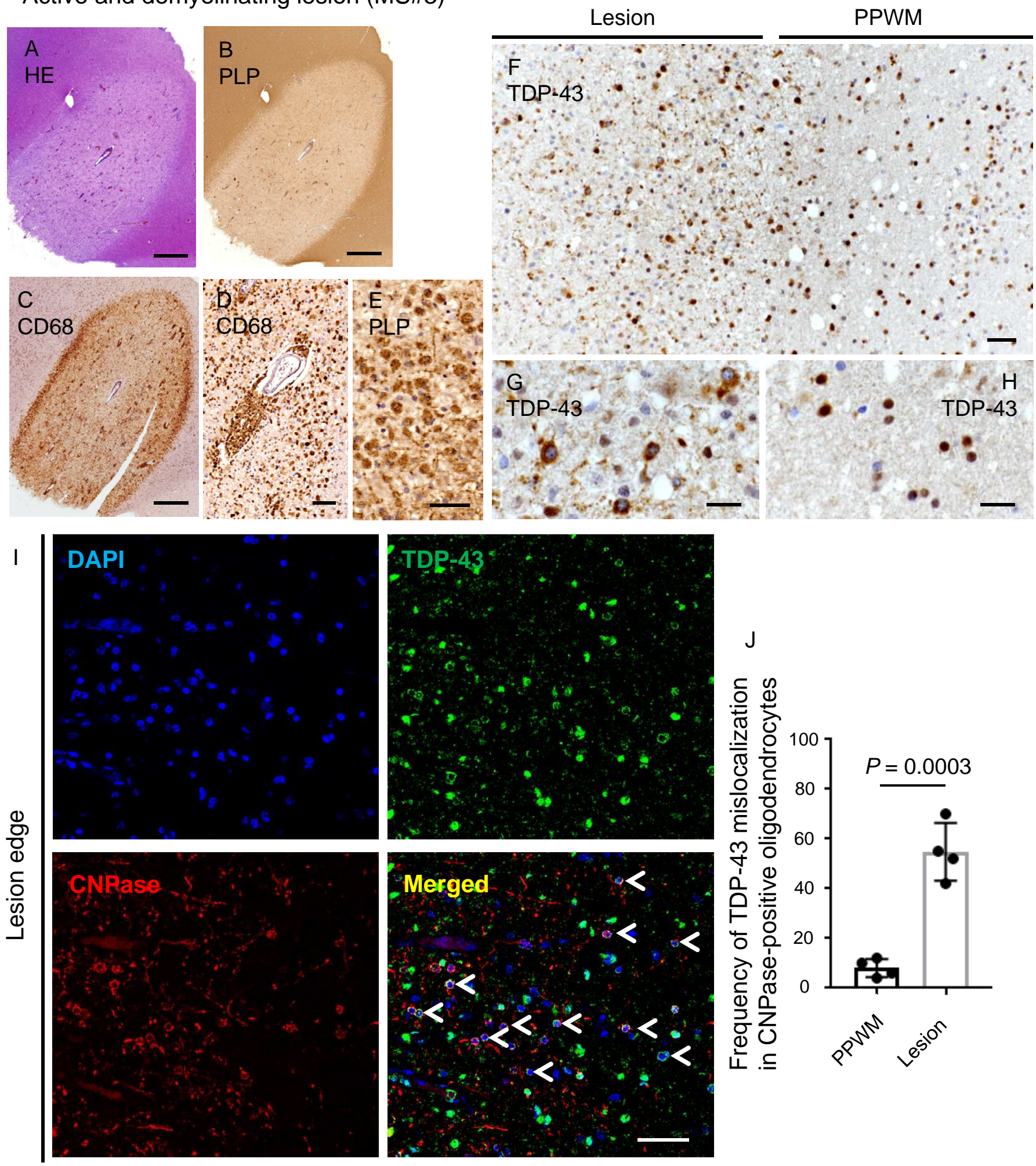


\section{Figure 3}

Mixed active/inactive and demyelinating lesion (MS\#10)

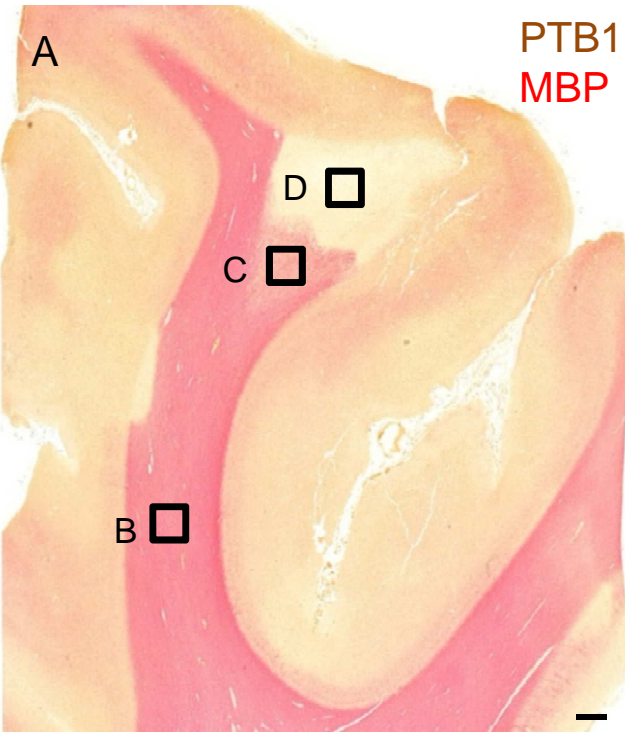

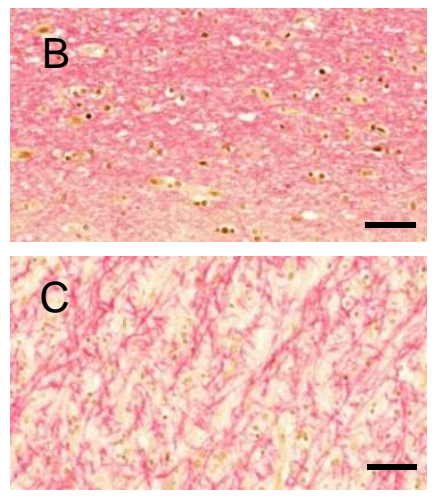

D
PTB1/CNPase
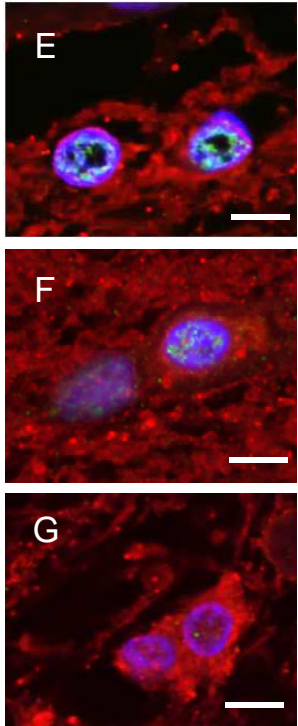

$\mathrm{H}$

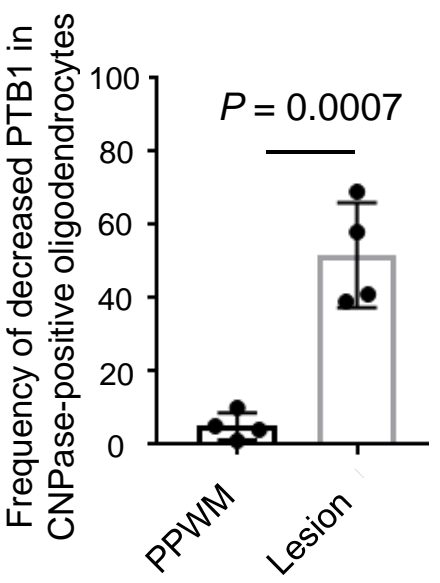

Mixed active/inactive and demyelinating lesion (MS\#6)
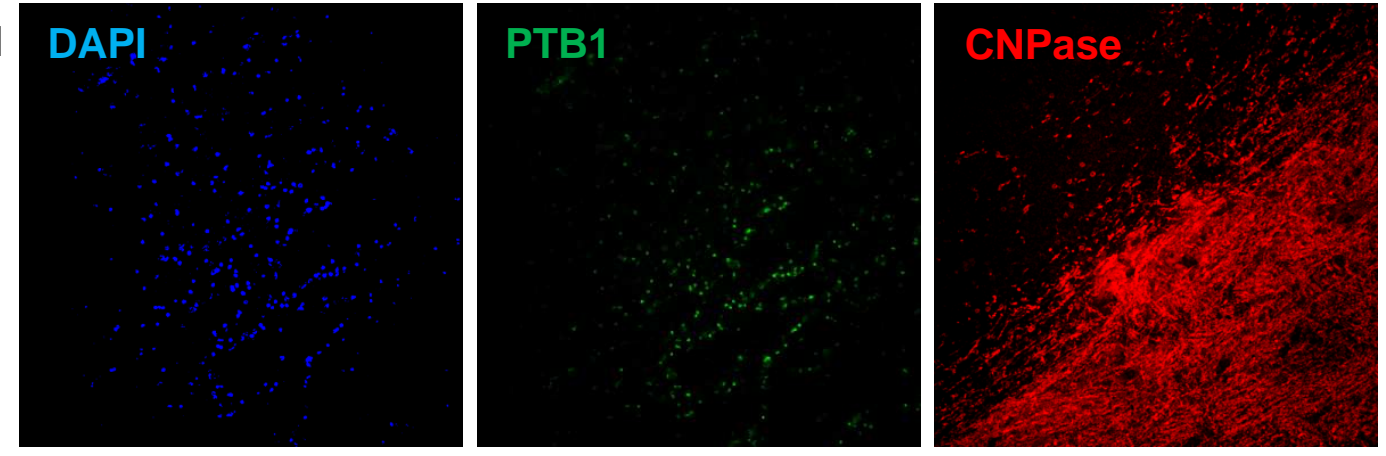

\section{Merged}
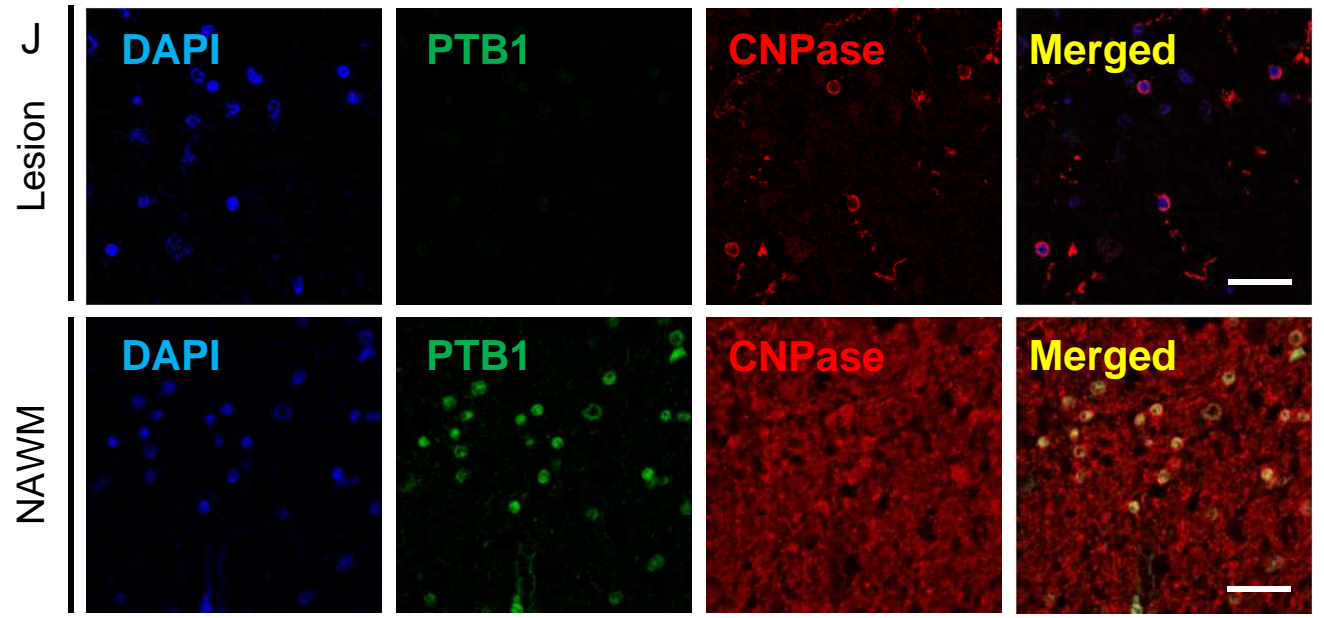

$\mathrm{K}$

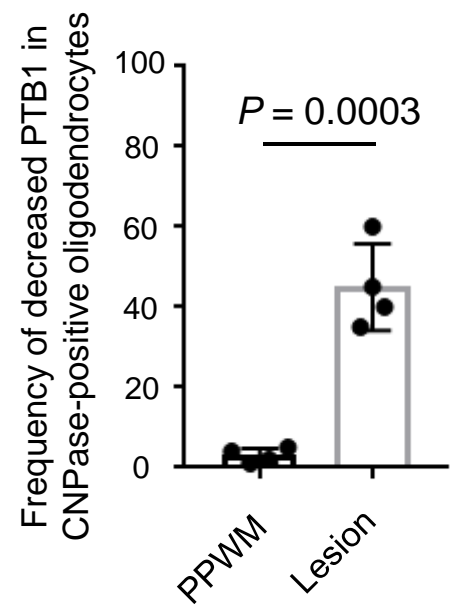


bioRxiv preprint doi: https://doi.org/10.1101/829457; this version posted November 5, 2019. The copyright holder for this preprint (which was not certified by peer review) is the author/funder. All rights reserved. No reuse allowed without permission.

\section{Figure 4}

Mixed active/inactive and demyelinating lesion (MS\#2)
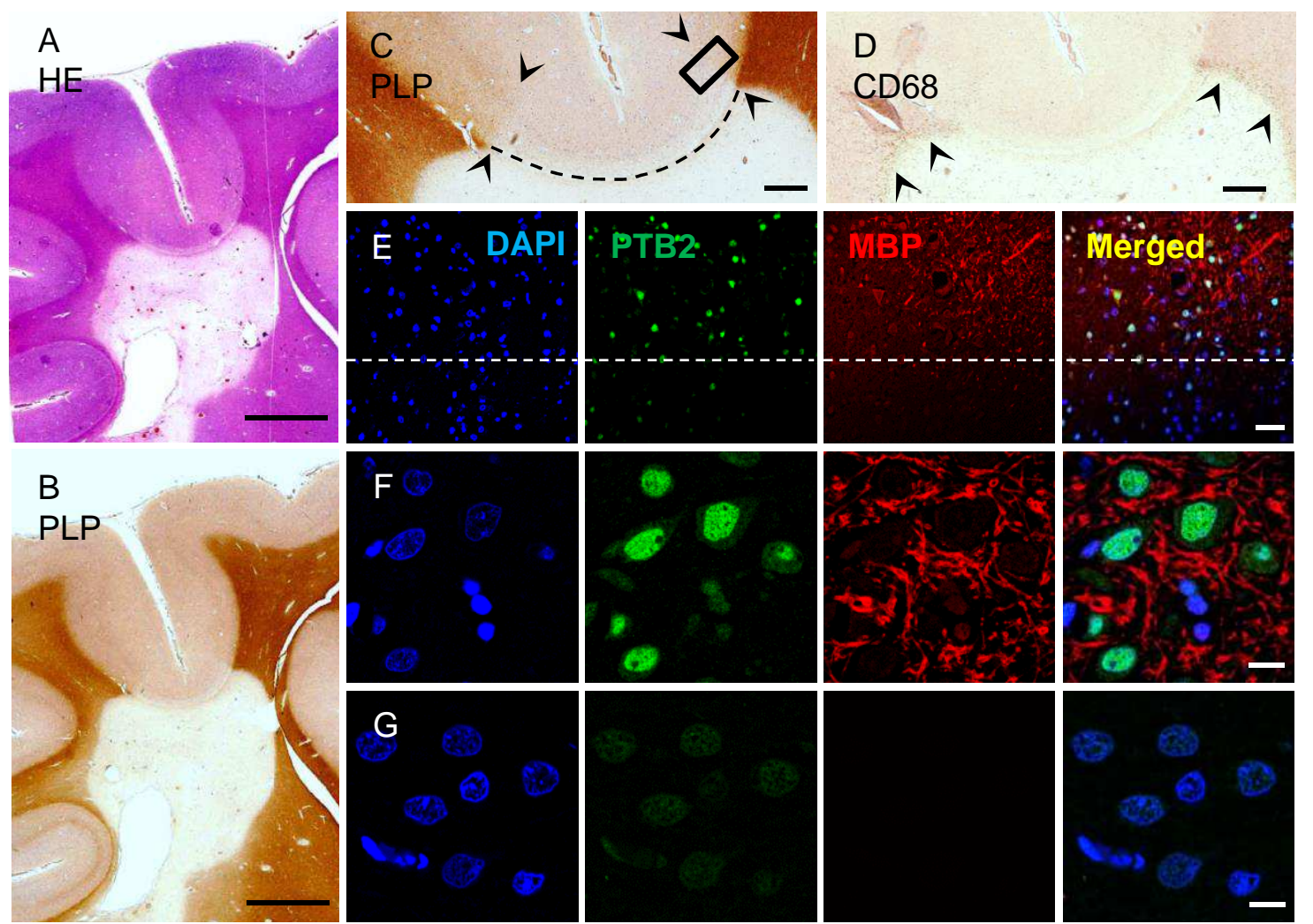

$\mathrm{H}$
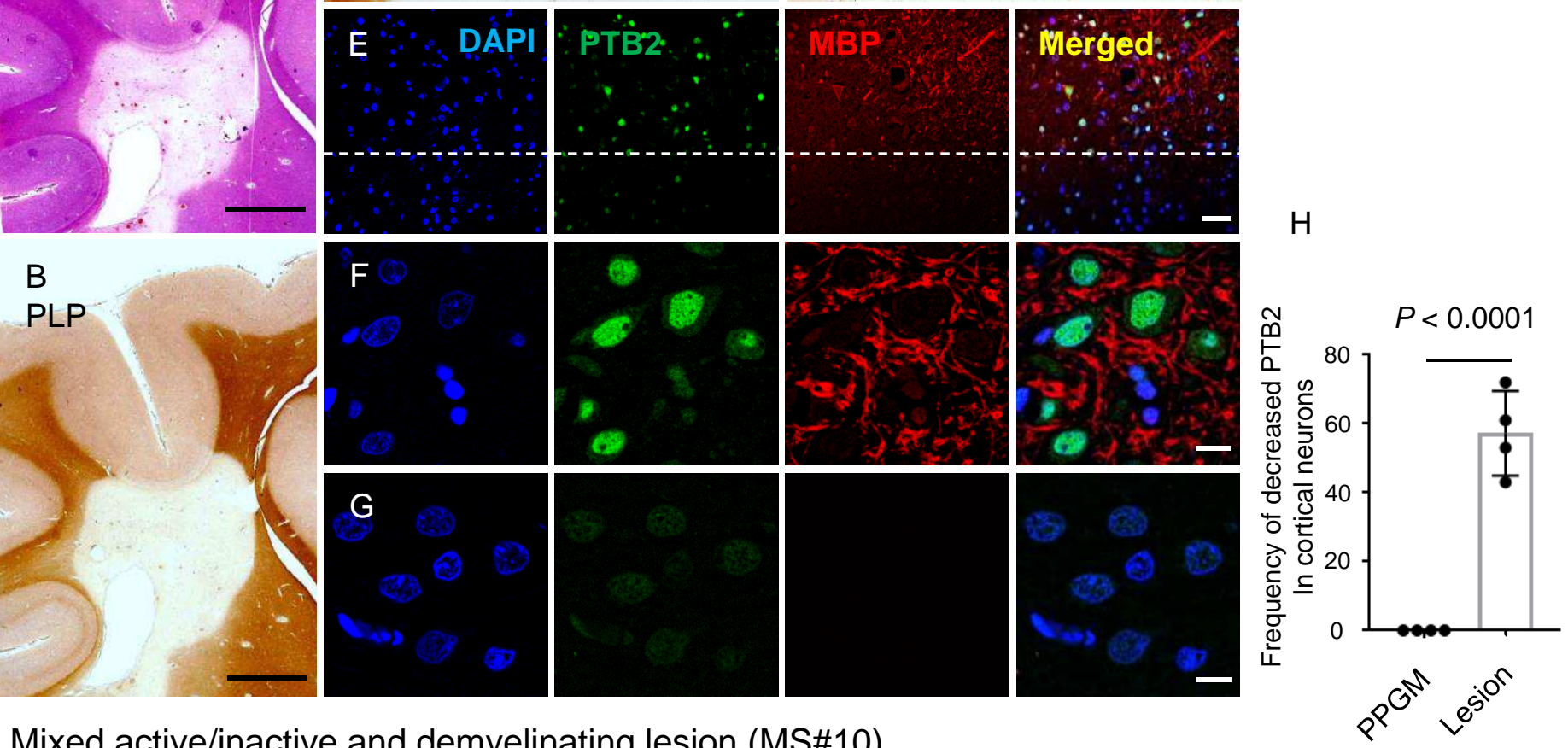

Mixed active/inactive and demyelinating lesion (MS\#10)
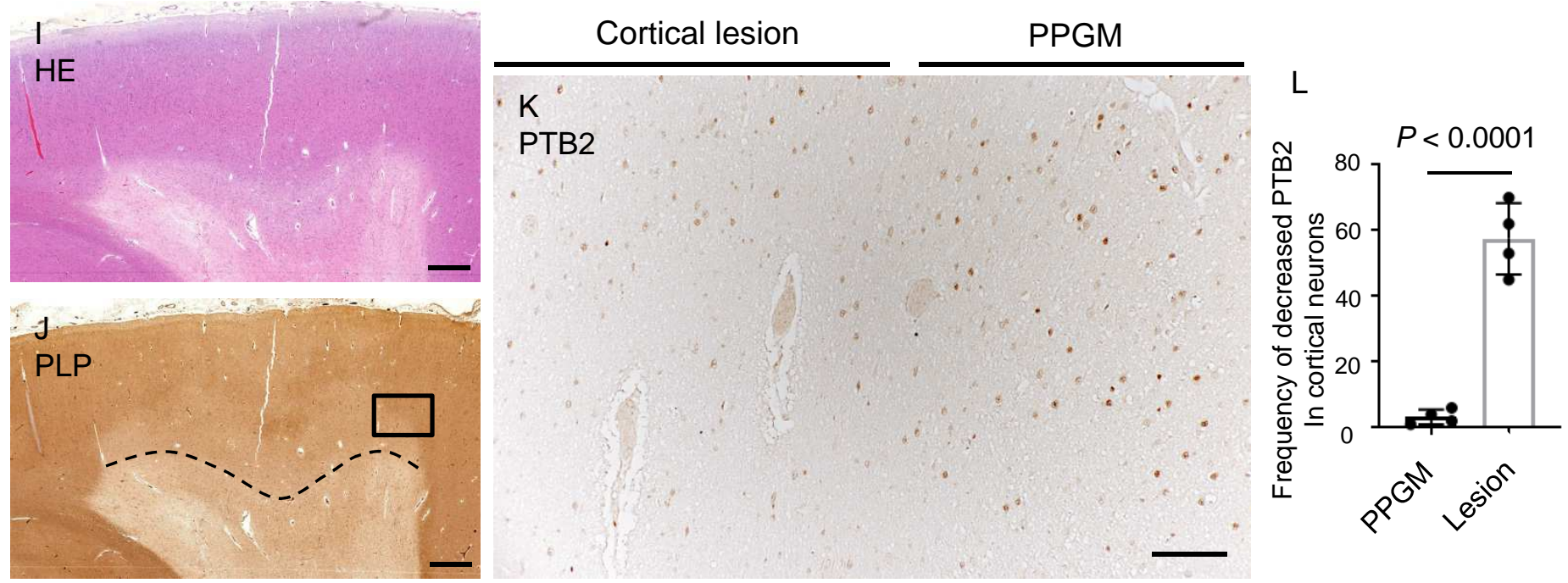
bioRxiv preprint doi: https://doi.org/10.1101/829457; this version posted November 5, 2019. The copyright holder for this preprint (which was not certified by peer review) is the author/funder. All rights reserved. No reuse allowed without permission.

Figure 5

A

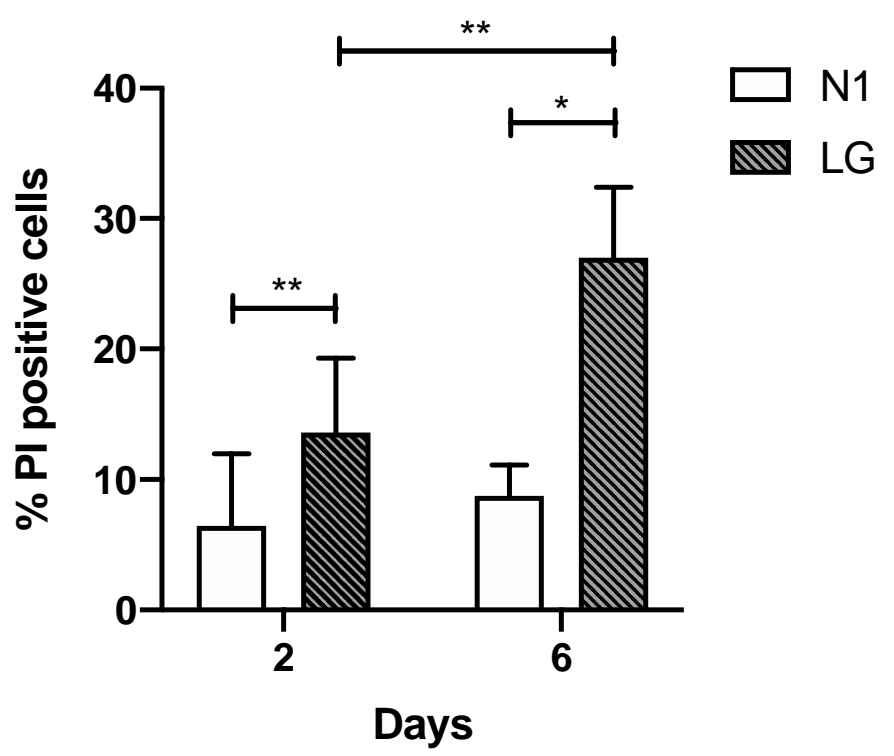

B

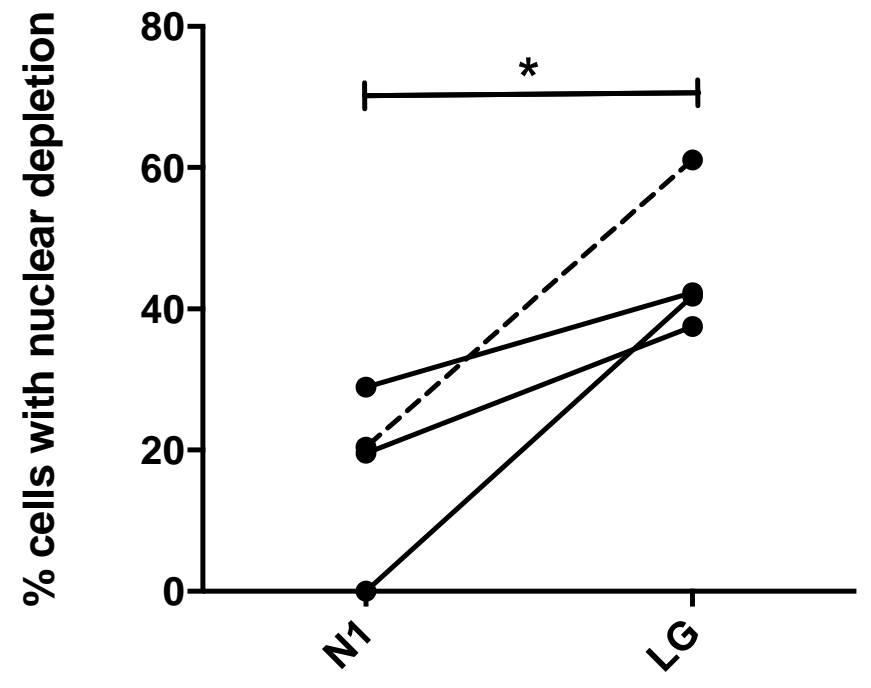

TDP-43

TDP-43/PI

C

04
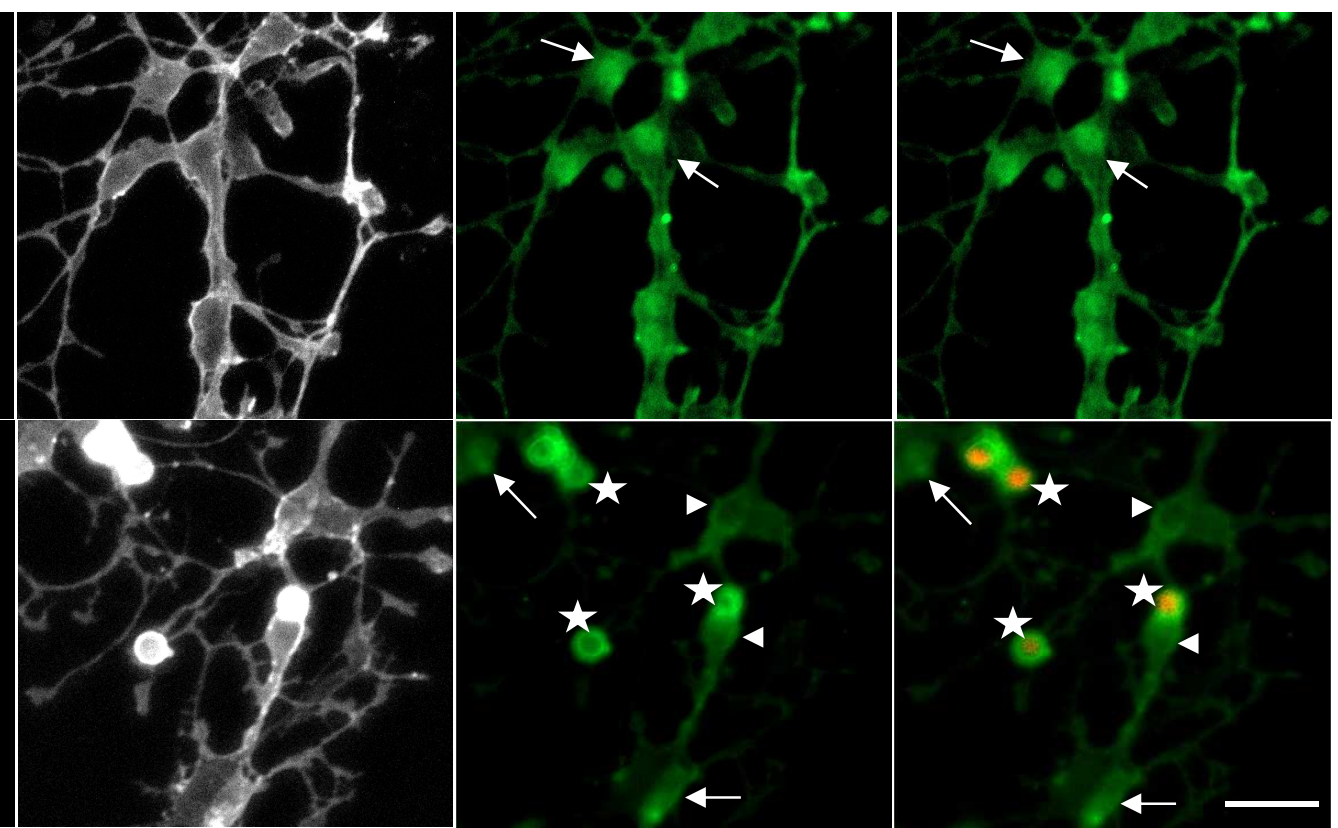
Table e-1 MS cases

\begin{tabular}{|c|c|c|c|c|c|c|c|c|}
\hline \multirow{2}{*}{$\begin{array}{l}\text { Patien } \\
\mathrm{t} \#\end{array}$} & \multirow{2}{*}{ Age } & \multirow{2}{*}{$\begin{array}{c}\text { Se } \\
x\end{array}$} & \multirow{2}{*}{$\begin{array}{l}\text { Clinical } \\
\text { subtype }^{*}\end{array}$} & \multirow{2}{*}{$\begin{array}{c}\text { White matter } \\
\text { lesion** } \\
\text { (number } \\
\text { examined) }\end{array}$} & \multicolumn{2}{|c|}{ Oligodendrocyte } & \multirow{2}{*}{$\begin{array}{c}\text { Gray matter } \\
\text { lesion }{ }^{\ddagger} \\
\text { (number examined) }\end{array}$} & \multirow{2}{*}{$\begin{array}{c}\text { Neuron } \\
\text { Decreased } \\
\text { nuclear PTB? }\end{array}$} \\
\hline & & & & & $\begin{array}{c}\text { TDP-43 } \\
\text { Proteinopathy }\end{array}$ & $\begin{array}{c}\text { Decreased } \\
\text { nuclear PTB1 }\end{array}$ & & \\
\hline 1 & 38 & $\mathrm{~F}$ & MS & I (1) & - & - & None & - \\
\hline 2 & 66 & $\mathrm{~F}$ & MS & $\mathrm{A} / \mathrm{I}(4)$ & - & ++ & LC (1) & + \\
\hline \multirow[t]{2}{*}{3} & 53 & $\mathrm{~F}$ & MS & $A(1)$ & ++ & - & None & - \\
\hline & & & & $\mathrm{A} / \mathrm{I}(1)$ & - & - & & \\
\hline $4^{\S}$ & 30 & $\mathrm{~F}$ & $T$ & $A(1)$ & - & - & None & - \\
\hline \multirow[t]{2}{*}{5} & 56 & $M$ & Prog & $\mathrm{A} / \mathrm{I}(1)$ & - & - & None & - \\
\hline & & & & I (3) & - & - & & \\
\hline 6 & 63 & $M$ & Prog & $\mathrm{A} / \mathrm{I}(3)$ & - & ++ & None & - \\
\hline 7 & 47 & $\mathrm{~F}$ & Prog & I (3) & - & - & None & - \\
\hline \multirow[t]{3}{*}{8} & 38 & $M$ & MS & $\mathrm{A} / \mathrm{I}(6)$ & - & - & $\mathrm{SP}(1)$ & - \\
\hline & & & & & & & IC (2) & - \\
\hline & & & & & & & LC (2) & + \\
\hline \multirow[t]{2}{*}{9} & 42 & $\mathrm{~F}$ & MS & $\mathrm{A} / \mathrm{I}(2)$ & - & - & SP (4) & - \\
\hline & & & & & & & IC (2) & - \\
\hline \multirow[t]{2}{*}{10} & 30 & $M$ & RRMS & $\mathrm{A} / \mathrm{I}(6)$ & - & +++ & $\mathrm{SP}(2)$ & - \\
\hline & & & & I (1) & - & - & LC (3) & ++ \\
\hline \multirow[t]{3}{*}{11} & 47 & $M$ & Prog & $\mathrm{A} / \mathrm{I}(2)$ & - & ++ & $\mathrm{SP}(3)$ & - \\
\hline & & & & & & & IC (1) & - \\
\hline & & & & & & & $\operatorname{LC}(1)$ & + \\
\hline \multirow[t]{2}{*}{12} & 42 & $\mathrm{~F}$ & Prog & $\mathrm{A} / \mathrm{I}(1)$ & - & ++ & $\mathrm{SP}(4)$ & - \\
\hline & & & & I (1) & - & - & $\operatorname{LC}(1)$ & ++ \\
\hline 13 & 60 & $\mathrm{~F}$ & Prog & $A(3)$ & ++ & + & None & - \\
\hline \multirow[t]{2}{*}{14} & 26 & M & RRMS & A (3) & - & - & None & - \\
\hline & & & & I (1) & - & - & & \\
\hline
\end{tabular}


${ }^{*} \mathrm{~A}$ : active lesion, $\mathrm{A} / \mathrm{l}$ : mixed active/inactive lesion, I: inactive lesion.

†TDP-43 mislocalization and/or decreased nuclear expression.

${ }^{\ddagger} \mathrm{IC}$ : intracortical lesion, LC: leukocortical lesion, SP: subpial lesion.

${ }^{\S} \mathrm{MS \# 4}$ : tissue was a biopsy from a tumefactive lesion.

${ }^{\star *}$ MS: multiple sclerosis with unclear clinical classification of the case, Prog: Progressive multiple sclerosis, RRMS: relapse-remitting multiple sclerosis. T: tumefactive 
Table e-2 Antibodies used for immunohistochemistry and immunofluorescence

\begin{tabular}{|c|c|c|c|c|}
\hline Antigen & & Type & Dilution & Source \\
\hline RNA-binding protein & TDP-43 (N-terminal) & Rabbit & $\underline{1: 1000}$ & Proteintech, Rosemont, IL, USA \\
\hline . & TDP-43 (1D3, phospho-S409/410) & $\underline{\text { Rat }}$ & $\underline{1: 100}$ & EMD Millipore, Burlington, MA, USA \\
\hline 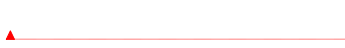 & $\underline{\text { PTB1 }}$ & $\underline{\text { Rabbit }}$ & $\underline{1: 100}$ & Abcam, Cambridge, UK \\
\hline & $\underline{\text { PTB2 }}$ & $\underline{\text { Rabbit }}$ & $\underline{1: 100}$ & Abcam \\
\hline$\Delta$ & FUS (11570-1-AP) & $\underline{\text { Rabbit }}$ & $\underline{1: 50}$ & Proteintech \\
\hline Oligodendrocyte/myelin & $\underline{P L P}$ & Rabbit & $1: 400$ & Sigma Aldrich \\
\hline & $\underline{\mathrm{MBP}(\mathrm{F}-6)}$ & Mouse & $\underline{1: 100}$ & Santa Cruz Biotechnology, Dallas, Tx, USA \\
\hline & $\underline{\text { CNPase }}$ & Mouse & $\underline{1: 100}$ & Abcam \\
\hline Macrophage & CD68 (KP1) & Mouse & $1: 300$ & Abcam \\
\hline
\end{tabular}

Formatted: Font: (Default) + Headings

(Arial)

\section{Formatted Table}

Formatted: Font: (Default) +Headings

(Arial)

Formatted: Font: (Default) +Headings

(Arial)

Formatted: Font: (Default) + Headings

(Arial), German (Germany)

Formatted: Font: (Default) +Headings

(Arial), German (Germany)

Formatted: Font: (Default) +Headings (Arial)

Formatted: Font: (Default) +Headings

(Arial)

Formatted: Font: (Default) + Headings

Arial)

Formatted: Font: (Default) +Headings

(Arial)

Formatted: Font: (Default) +Headings

(Arial) 